\title{
AS INJUNÇÕES AOS DOCENTES NA UNIVERSIDADE PÚBLICA: DE INTELECTUAIS A TRABALHADORES POLIVALENTES
}

\author{
THE INJUNCTIONS TO PUBLIC UNIVERSITY TEACHERS: FROM INTELLECTUALS TO \\ POLYVALENT WORKERS
}

LOS MANDATOS A LOS DOCENTES EN LA UNIVERSIDAD PÚBLICA: DE INTELECTUALES A

TRABAJADORES POLIVALENTES

Áurea de Carvalho Costa ${ }^{1}$

Resumo Apresentamos parte da pesquisa sobre a precarização do trabalho docente no Brasil. Trata-se de um texto de aprofundamento da discussão sobre docência no ensino superior no contexto atual. A hipótese é a de que esses docentes são submetidos à alienação e à precarização do trabalho, por meio de políticas de recrutamento, seleção, contratação e avaliação que os destituem do controle sobre o trabalho. Com base no referencial do materialismo histórico e dialético, utilizamos a análise documental para estudar o caso de uma universidade estadual. Identificamos como indícios da precarização do trabalho docente: as aplicações de avaliação institucional para gestão do pessoal docente; a redução dos quadros; a substituição de disciplinas por estágios e práticas em licenciaturas; o ensino à distância; a carência de políticas de valorização do aposentado; e as políticas que impõem aos ativos a lógica produtivista.

Palavras-chave ensino superior; intelectuais; universidade; trabalho docente; política educacional.
Abstract We present part of the research on the precariousness of teaching in Brazil. It is an in-depth discussion about teaching in higher education, in the present context. The hypothesis is that these teachers are submitted to the alienation and precariousness of labor by means of the recruiting, selection, hiring and evaluation policies, that deprives them of control over their work. Taking historical and dialectical materialism as reference, we utilized documental analysis to study the case of a state university. We identified as indications of the precariousness of teaching: the application of institutional evaluations for the management of the teaching staff; staff cuts; the substitution of disciplines for internships and teaching practice; e-learning; the lack of retirement recognition policies; and the policies that impose a productivist logic to the teachers in activity.

Keywords higher education; intellectuals; university; teaching work; educational policies. 


\section{Introdução}

Este texto traz uma problematização sobre a especificidade do docente do ensino superior na Universidade Estadual Paulista "Júlio de Mesquita Filho" (Unesp), com a finalidade de compreender o problema da precarização de seu trabalho na conjuntura neoliberal de reforma do Estado, que, por vezes, resultam em seu adoecimento, pois

[...] o trabalho intelectual do docente universitário pode ser somente a reprodução de sua cotidianidade, o afastamento de sua atividade humano-genérica, o seu esvaziamento, permitindo que o sofrimento psíquico seja uma das formas de expressão dessa falta de sentido de vida, possibilitada pelas relações de alienação (Gradella Júnior, 2010, p. 136)

Com base no referencial teórico-metodológico do materialismo histórico e dialético, objetivamos discutir as condições de produção do fenômeno da precarização do trabalho docente no ensino superior público, analisando a contradição entre as exigências de cumprimento de um papel social de intelectual e a realização de uma série de tarefas que identificadas como de gerenciamento da burocracia da universidade pública estatal.

Nosso objeto de pesquisa consiste no controle, por meio de diferentes mecanismos, do trabalho docente na Unesp. Assim, utilizamos documentos relevantes no momento da implantação da avaliação por meio de planilha, inédita nas universidades estaduais paulistas, procedendo à análise dos seguintes documentos: proposta de plano de carreira docente da Unesp, produzida pelo Conselho de Pesquisa, Ensino e Extensão (Cepe); instrução normativa Unesp $\mathrm{n}^{\circ} 1$ (UNESP, 1998); Plano de Desenvolvimento Institucional (doravante PDI) da Unesp, de 2009; resoluções Unesp n 84/1999 e $\mathrm{n}^{\circ}$ 85/1999; e portarias Unesp $\mathrm{n}^{\circ} 6 / 2000$, que subsidiam regimentalmente a instituição de uma planilha de avaliação do desempenho docente (UNESP, 1999a, 1999b, 2000).

Nosso pressuposto é o de que a especificidade da categoria docente do ensino superior consiste em se constituir de intelectuais. ${ }^{2}$ A categoria dos intelectuais surge historicamente no modo de produção estamental como um segmento autônomo e independente do grupo social dominante: os eclesiásticos, por exemplo, identificavam-se como uma casta distinta das castas dos servos e dos aristocratas, embora fossem organicamente ligados a esses últimos. Hoje, os intelectuais tradicionais são os filósofos, os literatos e os artistas, e estão divididos em urbanos (mais hierarquizados) e rurais (tradicionais, profissionais, como médicos, advogados, padres e outros). Enfim, são todos aqueles que, em decorrência da divisão fundamental do trabalho em execução e concepção, exercem os trabalhos relacionados à concepção (Gramsci, 1980). 
Portanto, desde o seu surgimento, a categoria docente fixa-se num determinado lugar da divisão social do trabalho. Por ser um tipo de trabalho imaterial, os docentes tendem a supervalorizar as suas especificidades, bem como a abstrair a realidade de que estão submetidos à condição assalariada como as demais categorias no contexto do capitalismo, apesar do nível cultural mais elevado. Tal contradição levou-nos a refletir se, analogamente ao que acontece com qualquer categoria de trabalhadores, os docentes de instituições de ensino superior - e especificamente os da Unesp - também são vulneráveis a alienação. ${ }^{3}$ Um indício dessa vulnerabilidade é a maneira como esses trabalhadores se identificam na sociedade, que deriva do fato de a sua autoimagem ser constituída historicamente por meio de duas perspectivas, ambas efeito da alienação:

[...] existe um apelo ao isolamento do intelectual ou defesa de um engajamento social, doutrinário e messiânico, por assim dizer, mas que ao mesmo tempo apresentam como ponto comum uma ideia de negação de vida e cotidianidade social, materialidades concretas dos sujeitos e do contexto sócio-histórico em que se encontram. Em Benda, por ver um caráter hedonista na vida comum e uma posição agnóstica em relação ao cotidiano, em sua visão à política. Em Mannhein, uma perspectiva idealista, ao posicionar os intelectuais como categoria social distante de uma perspectiva de classes, como se tais conflitos não fossem também vividos por tal categoria. Em Ortega e Croce, por uma visão liberal de Estado e de cultura, respectivamente, considerando, sobretudo para este último, sua trajetória de militância no partido liberal italiano (Souza, 2008, p. 169).

Inicialmente, apresentamos a constituição histórica de nossa categoria de análise, que é o trabalho docente na universidade pública, destacando-lhe os elementos necessários à compreensão das condições de produção do docente do ensino superior, tal como se apresentam hoje no modo de produção capitalista. Em seguida, debruçamo-nos sobre o caso das condições de trabalho da categoria docente na Unesp, por meio de uma análise documental. Nas considerações finais, ressaltamos o problema da alienação na categoria docente do ensino superior.

\section{A docência no contexto da ampliação e da mercantilização da educação superior}

Os docentes do ensino superior constituem uma categoria profissional nascida no seio da Igreja Católica na Idade Média. Em geral, os mestres eram clérigos que ministravam cursos isolados nos prédios pertencentes às diferentes ordens eclesiásticas, mesmo antes do nascimento das universidades tal como essas se apresentam na contemporaneidade. Em meados do século XII, 
o papa Inocêncio III criou as universidades de Paris e de Bolonha, que nasceu como um centro católico de estudos jurídicos. Em 1352, fundou-se uma faculdade de teologia sob a influência do papa Inocêncio VI. Contudo, a hegemonia da Igreja Católica sobre os estudos superiores se encontrava ameaçada por causa das lutas pela laicização do ensino universitário, pelo interesse tanto do poder estatal em financiar esses estudos quanto dos alunos e professores em fundar instituições independentes (Verger, 1990). Naquele momento, os estudos universitários ainda não tinham o caráter de universidade, surgido a partir da modernidade como Universitas, ou Studium Generale ou Comune e referindo-se a um "conjunto de pessoas, mestres e alunos, que participam do ensino dado nessa mesma cidade" (Gilson, 2001, p. 483). No decurso da história, a universidade, nos marcos do regime democrático republicano, foi se institucionalizando como um lócus autônomo de produção de conhecimento e de formação de profissionais de alto nível, pautado no entendimento de que a ciência compreendia a investigação teórica com implicações práticas, de modo que havia mediações entre a sua produção e a sua transformação em tecnologias, a serem posteriormente assimiladas pelo capital como forças produtivas. Já a dimensão do ensino deveria visar à formação, que compreende dimensões muito além da formação para o trabalho (Chauí, 2003).

Hoje, as universidades se tornaram complexas de modo a se organizarem em instituições de ensino superior, faculdades, centros universitários e universidades. Devem não apenas ter uma universalidade de áreas, mas também desenvolver atividades de pesquisa e ensino, e relações mais diretas com a comunidade, mediadas pelas atividades de extensão (Dias Sobrinho, 2003). Porém, nem todas as instituições de ensino superior cumprem tais requisitos, daí a necessidade da diferenciação, que implica um maior ou menor espaço para a produção do conhecimento em relação à sua reprodução, com fins de formação de profissionais de alto nível. Isso não se dá de maneira neutra. Compreende a dimensão política, desde o contexto histórico do nascimento da universidade, no qual a Igreja disputava seu controle com o Estado, e cuja dimensão apreendemos sob a mediação da luta de classes.

$\mathrm{Na}$ atualidade, observa-se como as instituições superiores de ensino com estatuto de universidades públicas privilegiam, em sua maioria, a atividade de pesquisa e, ao mesmo tempo, são espaços em que predominam alunos da classe hegemônica, de modo que essa classe social tem acesso privilegiado aos saberes sobre os processos de produção do conhecimento. Indagamo-nos se justamente nessa universidade, por causa da tendência à reprodução de quadros originários da classe burguesa para a produção do conhecimento, não se estariam reproduzindo ideologias que conformam um determinado perfil profissional, o do cientista que estabelece uma relação mistificada com a sua atividade de trabalho. 
Na conjuntura neoliberal temos visto um processo de transmutação do direito à educação em serviço educacional, ou seja, um direito, que é produto de determinadas relações sociais, mas que passa a ser visto como serviço privado, com valor de uso e valor de troca. Conforme o censo de 2009, no Brasil 2.069 instituições de ensino superior são privadas e 245, públicas (Instituto Nacional de Estudos e Pesquisas Educacionais Anísio Teixeira, 2010). Esse é o cerne da mercantilização do ensino superior. E é ele que coloca novas exigências aos docentes, que passam a sofrer a extração da mais-valia pelas mantenedoras, e também produz efeitos sobre os docentes assalariados das universidades públicas, as quais não extraem mais-valia dos servidores nem geram lucros, mas, mesmo assim, submetem esses docentes à lógica empresarial e aos critérios de produtividade. Chauí (2003) mostra que a universidade, paulatinamente, abandonou a identidade de instituição social que colabora para o estabelecimento do modelo de Estado republicano, a fim de assumir uma configuração de organização social mais instrumental. Hoje, a universidade é gerida de forma mais racionalizada e comprometida com a produtividade e a transformação do conhecimento em meios de produção (tecnologias), sem mediações. Isto contribui para que ela se torne, cada vez mais, heterônoma no âmbito do modo de produção capitalista.

Esse novo modelo de universidade impõe aos seus servidores, especialmente aos docentes, uma forma de relação laboral, bem como uma relação com o tempo de produção que, antes, mais pautada pela velocidade da produção fabril, do que da produção do conhecimento (Chauí, 2003). Assim, o método de organização do trabalho do mundo da produção tem invadido a escola em todos os níveis. Se nos detivermos na dinâmica interna das instituições escolares, constataremos que, mesmo antes da reforma nas funções do Estado que marcou a passagem do século XX para o XXI, a organização taylorista-fordista do trabalho já guardava uma racionalidade que informava a organização do trabalho escolar, ampliando-lhe as tarefas docentes, potencializando o trabalho de atendimento a números cada vez maiores de alunos e buscando incrementar os níveis de controle sobre o seu trabalho (Gramsci, 1980).

Desde os seus primórdios, o capitalismo impõe à classe trabalhadora o trabalho alienado como única forma de provimento da reprodução biológica e social. A categoria docente não só se submete a essa lei geral, como também a reproduz nas suas práticas pedagógicas. Os docentes do ensino superior, na condição de trabalhadores, sofrem a alienação do trabalho desde o processo de qualificação, na forma do aligeiramento, que incorre no rebaixamento da formação inicial, nos cursos de graduação e nos tecnológicos; da degradação das condições laborais; da perda do poder aquisitivo dos salários; e da própria transformação da formação universitária num serviço. Hoje, em todos os setores da economia, demanda-se a formação do trabalhador polivalente, uma formação que prepare os trabalhadores para situações novas, administração 
de conflitos, detecção e resolução de problemas, elaboração de propostas criativas etc. Atualiza-se, então, a função social da educação de preparação para o trabalho, com o objetivo de formar trabalhadores com perfil polivalente. Instala-se, com isso, uma contradição na categoria docente do ensino superior, pois, por um lado, a natureza de sua atividade intelectual não permite a adequação às metodologias e ritmos da produção de bens sem sofrimento, mas, por outro, seu trabalho não pode deixar de ser determinado pelo contexto no qual esse trabalhador se encontra inserido:

O trabalhador intelectual docente tem como base de sua atividade, justamente, a produção científica, o que, em primeira instância, seria qualitativamente superior às outras atividades. Entretanto, isso não ocorre de uma forma linear, como um mero reflexo da realidade, já que a atividade humano-genérica se apresenta enquanto possibilidade, mediada pelas relações sociais que, no modo de produção capitalista, apresentam-se de forma alienada, ou seja, heterogêneas, como cotidiano em si (Gradella Júnior, 2010, p. 137).

No medievo o ensino de estudos superiores nas universidades era determinado pelas disputas entre Estado e Igreja pela universidade, essa entendida como lócus de irradiação de ideologias, com consequências sobre as práticas pedagógicas e a produção de conhecimento dos intelectuais tradicionais. Da mesma forma, no contexto do capitalismo, é a metodologia da organização do trabalho no mundo da produção que passa a determinar tais práticas, de modo que a cultura do desempenho impõe a necessidade de responder às exigências de um perfil, convertendo-se em guia tanto para a sua formação quanto para a atuação:

Na cultura do desempenho, constantemente tanto a agenda do professor como a do aluno, no que diz respeito ao processo de ensino aprendizagem, têm de ser abandonadas em função daquilo que foi definido pelas autoridades educacionais como indicadores de bom desempenho. [...] os professores imersos nessa cultura vão perdendo o interesse em trabalhar com atividades e aspectos que não estejam diretamente relacionados com os indicadores de desempenho (Santos, 2004, p. 3).

O Estado oferece uma formação inicial cada vez mais fluida, versátil, a ser complementada durante a trajetória ocupacional, adequada aos perfis demandados pelo mercado, cambiante a cada momento, em detrimento da formação inicial sólida, que é uma condição sine qua non para a atuação profissional autônoma. No que tange às exigências para os docentes do nível superior, fragmenta-se a formação continuada em níveis diversos, tais como os aperfeiçoamentos, as especializações, os mestrados profissionais, a pós-graduação stricto sensu, com prazos limitados a dois ou três anos para 
os mestrados e a quatro anos para os doutorados, além dos pós-doutorados (Gradella Júnior, 2010).

O magistério é uma profissão cuja peculiaridade é a elaboração de conhecimentos e a socialização do patrimônio cultural da humanidade. Esses conhecimentos são apresentados por meio de práticas pedagógicas, de acordo com o desenvolvimento e a faixa etária dos alunos, e, no caso do docente do ensino superior, o trabalho

[...] predominantemente intelectual que caracteriza o docente universitário tem como produto as ideias, as teorias e se realiza na produção/reprodução dos conteúdos ideológicos. Isso coloca em pauta a educação, pois, antes de ser mera função informativa e comunicativa, o compromisso educativo ou a atividade fim da universidade é a formação, não só dos sujeitos humanos, mas também a dos profissionais que estarão em relação de trabalho na sociedade em geral. Mais especificamente, um moto contínuo que estará formando profissionais na função de educadores e pesquisadores que, por sua vez, também estarão formando as crianças e adolescentes (Gradella Júnior, 2010, p. 135).

Assim, não basta uma formação meramente pragmática, uma preparação para vender serviços no mercado, embora essa dimensão não deixe de estar presente. O professor é um elaborador de conhecimentos científicos, suas práticas rompem com o cotidiano, impõem uma visão de mundo complexa, elaborada, superior, subvertendo toda forma de mistificação e preconceito. Trata-se de uma categoria com especificidades, mas que também pertence à classe trabalhadora, exercendo profissionalmente o trabalho de intelectuais os quais, independentemente de serem comprometidos com um ou outro ideal de homem e de sociedade, têm responsabilidade sobre a formação (ou deformação) de seres humanos e são fundamentais no processo de humanização (Gramsci, 1980).

\section{As injunções aos docentes do ensino superior: o caso da Unesp}

Nas últimas três décadas, como reação à crise crônica, o capitalismo impôs três diretrizes para recuperar e ampliar suas taxas de lucro. A primeira delas foi a gestão da res publica com metodologias de gerenciamento empresarial, concretizada na forma de políticas privatizantes, por meio das vendas de patrimônio, das parcerias público-privadas e da criação da instituição pública não estatal (Brasil, 1995). A segunda diz respeito às relações internacionais dos países de economia dependente com os do capitalismo central, ocorrendo a desnacionalização, a abertura das fronteiras nacionais ao comércio imperialista e a integração à economia internacional imposta pelos países de capitalismo 
central e suas agências. A terceira é a nova organização do trabalho, sob a forma de ataques aos direitos sociais e trabalhistas, reestruturação produtiva, deslocamento industrial para novas regiões a fim de explorar ao máximo a classe trabalhadora, uso de tecnologias para preservar e aumentar a lucratividade com menor número de trabalhadores assumindo mais tarefas, terceirização da produção e dos serviços, e intensificação das responsabilidades dos trabalhadores.

A reestruturação produtiva não deixou de afetar os docentes do ensino superior público. No Brasil, o neoliberalismo foi assumido como política oficial do Estado desde o governo de Collor de Mello (1990-1992), e os governos que lhe sucederam implantaram uma estrutura jurídica, política e ideológica sustentada na lógica privatista. A regulamentação da lei do voluntariado (Brasil, 1998b) e a ratificação das parcerias público-privadas (Brasil, 2004) têm sido dois instrumentos importantes nos processos de privatização desde então, na medida em que estimulam a intervenção de setores da sociedade civil na gestão das políticas de Estado. Nas universidades públicas, a gestão decorrente do novo modelo de Estado e as novas práticas de gestão têm levado à precarização de sua estrutura e à diminuição de recursos financeiros públicos, bem como de recursos humanos, uma vez que se tem priorizado o nível do ensino fundamental, em detrimento de outros. É notória a focalização das políticas educacionais em políticas como o Fundo de Desenvolvimento do Ensino Fundamental e Valorização do Magistério (Fundef), que elegeu como prioridade o ensino fundamental, e, a partir de 2010, o Fundo de Desenvolvimento da Educação Básica e Valorização dos Profissionais da Educação (Fundeb), que estendeu a priorização ao nível básico. Apesar de o investimento nas licenciaturas em cursos de graduação plena, com vistas à formação inicial dos professores, ser um elemento decisivo para a valorização da educação básica, isso não foi considerado em ambas as leis que estabelecem fundos, daí a priorização do nível básico concomitante com uma política de expansão do ensino superior pela via das instituições de ensino superior privadas. Em virtude da escassez de recursos para as universidades públicas, tem-se estimulado a captação das fontes alternativas de investimento, por meio de parcerias com instituições privadas, sob a forma de organizações não governamentais, fundações e empresas - salientando-se que todas são organizações de direito privado cujas funções são coadjuvantes na implantação de políticas estatais - para a realização de projetos de pesquisa, ensino e extensão. No planejamento, na gestão e no financiamento da universidade em estudo constam como ações, com vistas ao cumprimento do objetivo de ampliar recursos para o financiamento da universidade, as seguintes:

1) Promover ações junto ao governo e à Assembleia Legislativa, visando ao aumento real do repasse financeiro do Estado para a Universidade; 
2) Atuar na captação de recursos externos, não governamentais e governamentais, incluindo aqueles provenientes das leis de incentivos fiscais;

3) Aprimorar área voltada ao planejamento estratégico com o objetivo de incentivar a prospecção e captação de recursos financeiros;

4) Aglutinar forças com outras instituições científicas, universitárias, educacionais e sociais, desenvolvendo ações para que as metas de financiamento em ciência, tecnologia, artes e educação, que constam do Plano Nacional de Educação, sejam cumpridas (UNESP, 2009a, p. 33).

Assim, ocorre um processo de privatização da educação, mediada pelos valores da doutrina liberal, tais como a meritocracia, a competição, o individualismo, a mercantilização que se traduz em políticas públicas, como as parceiras público-privadas. Além disso, a captação de verbas tem se dado também por meio de projetos de docentes, sejam eles individuais ou em grupo, apresentados às agências públicas de fomento. Na medida em que a educação superior pública passa a depender da iniciativa privada para a sua manutenção, é submetida à imposição de diretrizes dos interesses privados como contrapartida desse financiamento.

Quanto à gestão, observa-se uma dialética da centralização/descentralização, em que se dá a imposição da lógica gerencial, com desconcentração das tarefas e das responsabilidades, enquanto o poder decisório concentra-se nos órgãos diretamente vinculados aos staffs superiores do governo. Trata-se da apropriação, pelos gestores da universidade, da lógica do mercado, levando a uma nova estruturação, com maximização da utilização da estrutura e dos recursos humanos e minimização do investimento, especialmente, o público, incorrendo na mercadorização da universidade, "sob o impacto das teorias gerenciais das empresas capitalistas imersas na suposta anarquia do mercado, hoje estruturado por organismos multilaterais a agirem em toda a extensão do planeta" (Silva Junior e Sguissardi, 2001, p. 75).

No caso do estado de São Paulo, a proposta de previdência para os servidores públicos, e entre eles os docentes de universidades públicas paulistas, denominada SPPREV, foi regulamentada por medidas provisórias e projetos de lei do Executivo federal, aprovadas em um congresso nacional submetido às diretrizes neoliberais. Durante os governos do Partido da Social Democracia Brasileira (PSDB), no período de 2001 a 2006 e de 2007 a 2011, deu-se a concretização dessa política, na forma de crescimento do ensino superior sem investimento público, com a expansão das vagas na universidade pública.

A avaliação institucional é um dos aspectos que mais refletiu a reforma do Estado na universidade:

A avaliação da educação superior ganhou importância central em todos os países que, no contexto da reforma dos Estados e com finalidade de alcançar maior competitividade 
internacional, empreenderam políticas de transformação desse nível educativo. Entendida como elo importante das reformas, a avaliação da educação superior transborda os limites propriamente educativos e se situa nos planos mais amplos da economia e da política (Dias Sobrinho, 2003, p. 54).

Nas universidades, a avaliação teve um efeito sobre a categoria docente, destacando-se, no campo da pesquisa, sua produtividade e, no ensino, o desempenho de seus alunos, entendido como decorrência, sem mediações, do trabalho do docente, o que causa, imediatamente, sofrimento psíquico:

Ao ser avaliado em qualquer situação de trabalho (ensino, pesquisa e extensão), pela instituição ou por órgãos de fomento e financiamento, a produtividade é definida quantitativamente, independentemente da área de conhecimento e das condições de trabalho do sujeito, contribuindo para que esse trabalhador seja instado a competir no mesmo nível da área de conhecimento daqueles que se encontram em condições de trabalho bem mais adequadas, seja em termos das condições materiais, bem como pela história do curso/instituto/universidade. Essa forma de solicitação de produtividade contribui em muito para o maior aparecimento de distúrbios de ordem psíquica (Gradella Júnior, 2010, p. 138).

Os docentes da Unesp têm suas responsabilidades atribuídas por meio da resolução $n^{\circ}$ 85/1999 e da portaria $n^{\circ}$ 6/2000, responsabilidades que compreendem o exercício de atividades de ensino, pesquisa, extensão e gestão. Até 2007 havia liberdade para que o professor dividisse o seu tempo, podendo priorizar uma dimensão, em detrimento de outra, desde que todas fossem contempladas durante o triênio, de forma articulada, e que se respeitasse a determinação da Lei de Diretrizes e Bases da Educação Nacional (LDB) de que cada professor ministre uma média de oito horas-aula por semana durante todo o ano letivo. À medida que a Unesp vai se convertendo naquilo que Chauí (2003) denominou universidade operacional, e se identifica cada vez mais como organização social, vão se criando mecanismos de imposição, vigilância e avaliação para aferir o seu sucesso na imposição desse novo modelo, surpreendentemente, fazendo uso das próprias instâncias colegiadas, as quais reproduzem na escola a democracia representativa estatal, com anuência dos próprios docentes que se encontram nessas instâncias decisórias.

Em 13 de novembro de 2007, no âmbito do Conselho de Ensino, Pesquisa e Extensão da Unesp, foi aprovada a planilha de aferição do desempenho, instituindo novos critérios de avaliação e a ser aplicada pela Comissão Permanente de Avaliação a partir de janeiro de 2008. Trata-se de um instrumento que não só detalha as tarefas concernentes a cada dimensão, como também estabelece valores sob a forma de pontos. Os dados para a pontuação na planilha devem ser colhidos do Currículo Lattes do docente, entregue 
anualmente junto com a planilha, com a pontuação do ano. Ao final de cada triênio, o docente deve apresentar a planilha completa, um relatório de atividades e o plano para o próximo triênio.

O instrumento da planilha, que se apresenta sob um modelo para avaliar professores de diversas áreas de conhecimento, constitui-se de uma lista de 239 atividades, divididas nos itens ensino, pesquisa, extensão e gestão, incluindo pós-graduação como item extra, cujas pontuações variam de 0,25 a 30. É necessário obter, no mínimo, 70 pontos, distribuídos por, pelo menos, três itens. Previa-se o cumprimento de itens compulsórios, que foram retirados em 2013. As atividades de 30 pontos são as de gestão. Nesse instrumento de aferição da produtividade docente, a atribuição de pontuações e a escolha de atividades que merecem lugar na planilha se estabelece segundo critérios obscuros, com a supervalorização da dimensão da gestão. Isso concorre para a alienação, entendida como relação estranhada com o trabalho e a perda dos conteúdos e do controle sobre ele, uma vez que consagra o uso da avaliação institucional como forma de controle externo do trabalho. A planilha foi bastante criticada nos dois fóruns de avaliação docente promovidos, em 2011, pela própria Unesp. Os diversos departamentos contribuíram para a produção de um documento de 141 páginas nas quais se sintetizam todas as críticas recolhidas dos professores dos 23 campi da universidade (UNESP, 2011). Entretanto, o instrumento é cada vez mais validado no âmbito da reitoria e, desde 2008, tem servido como critério para admoestações, reduções de jornadas e desligamento de docentes que não alcancem os níveis mínimos exigidos.

Entendemos que as avaliações nas instituições públicas constituem uma forma de preservação da coisa pública, mas devem ser concebidas, planejadas e realizadas com vistas a reconhecer e a valorizar a atuação dos servidores docentes e técnico-administrativos, bem como estimular o aprofundamento dos conhecimentos sobre cada instituição. A utilização das avaliações como estratégia para imprimir um ritmo crescente de produção intelectual, no caso da Unesp, consiste num uso reducionista desse importante recurso pedagógico:

A avaliação da universidade pelo Estado, entendida e realizada sem se preocupar com os contextos, a inserção social, o sentido, a natureza, a identidade e as condições concretas de existência da instituição, implica maior controle e disciplinamento do ensino, da pesquisa, do trabalho intelectual, dos processos de produção e difusão do saber (Coelho, 2003, p. 123).

Nesse sentido, destitui-se a categoria docente do protagonismo da organização da avaliação institucional, que é assumida pelo governo sem o respaldo do debate acadêmico sobre as diretrizes para o desenvolvimento da ciência e da tecnologia no país, orientando-se apenas por critérios mercadológicos: 
Observa-se muito claramente que o Ministério [da Educação] é o grande e único protagonista dessa avaliação. Não há dúvida de que ela é eficientíssima para os propósitos governamentais e fornece um mapeamento geral e momentâneo para o mercado (Dias Sobrinho, 2003, p. 78).

O modelo de avaliação por desempenho abre precedentes para a introdução de critérios que não podem ser controlados pelo docente, como a aprovação de projetos por órgãos de fomento, as orientações com bolsa de estudos e o exercício de atividades de gestão que exigem a eleição do representante para atuar nos órgãos colegiados, ou ainda a exigência de que os docentes realizem captação de verbas por meio de projetos, transformando os pesquisadores em "empreendedores" - atividade estranha à natureza laboral do ensino e da pesquisa (UNESP, 2009a). Ademais, a lógica mercantilista impõe-se de modo que:

O processo de mercantilização da educação vai se expressar quando o quantum de produção científica fornece a ilusão de sermos "proprietários" de algo e autônomos, pois obtemos o reconhecimento da academia e, assim, podemos reclamar uma maior fatia das verbas da universidade e dos órgãos de fomento (Gradella Júnior, 2010, p. 138).

Tal avaliação de desempenho, como foi proposta no plano de carreira da universidade em estudo (UNESP, 2010) privilegia distorções como as de que a quantidade de publicações denota alta produção científica, baseada numa compreensão que privilegia a quantidade em detrimento da qualidade. Tais critérios foram estabelecidos como respostas dos gestores da universidade às exigências internacionais, que produzem índices e os impõem à comunidade acadêmica de forma dogmática.

Um exemplo disso é o índice h, criado por Hirsch em 2005, o qual considera produtivo o pesquisador que tem determinado número de artigos publicados com o mesmo número de citações por artigo, por exemplo, se escreveu três artigos, deverá ter três citações de cada um deles. Assim, um autor que publica poucos artigos muito citados não é considerado produtivo, e também não se tiver muitos artigos pouco citados. Embora a adoção do índice h ainda não seja oficial na universidade em estudo, exprime bem o espírito do produtivismo. As análises sobre tal avaliação indicam que se abstrai a forma como as diferentes áreas de conhecimento fazem uso do material bibliográfico, homogeneizando as diferenças, bem como induzindo à autocitação e não considerando nem o sentido nem o contexto em que as citações foram feitas (Marques, 2013).

No âmbito de relações produtivistas com a pesquisa, cada docente pesquisador passa a praticar uma equiparação de toda a produção acadêmica 
sem as devidas diferenciações entre publicações decorrentes de pesquisas e estudos, registros de atividades de extensão - como relatos de experiência -, compilações e outros, não considerando as especificidades das produções em diferentes áreas do conhecimento, da arte e do pensamento. Ademais, os referidos documentos desvalorizam outras atividades:

A confusão entre produção e quantidade de publicações é bastante frequente e inseparável de uma simplificação grosseira no sentido da amplitude do trabalho intelectual, de uma compreensão reducionista, limitada e pobre da produção acadêmica, da redução da qualidade à quantidade e do incentivo à publicação de textos de discutível valor cultural, científico, artístico e filosófico. Além das publicações, são ainda inerentes ao trabalho e à produção dos professores a leitura, o estudo, a reflexão, a busca do saber, o cultivo do pensamento, a compreensão, o amadurecimento e o repensar dos conceitos, das articulações teóricas e das questões metodológicas, a realização das experiências, a revisão de seus resultados e conclusões, a discussão e a mudança dos currículos, a orientação e a formação dos estudantes, o repensar e recriar da prática, o preparo das aulas e das conferências, a correção de trabalhos, a realização de pesquisas, a produção de trabalhos escritos, a elaboração de relatórios, a participação em congressos, em bancas de teses e de concursos [...] (Coelho, op. cit., p. 124).

Para além dessas tarefas, há que se acrescentar o ranqueamento dos periódicos, editoras e eventos científicos, que eleva a concorrência entre publicações em algumas mídias, envolvendo os docentes numa situação análoga à dos jogos de azar, em que a produção não responde mais à demanda do pesquisador de publicização de suas descobertas, mas de captação de verbas e manutenção do próprio emprego:

[...] a quantidade de publicações precisa ser tomada cum grano salis, pois sabemos que essa quantidade pode exprimir pouca qualidade e pouca inovação porque: a) os chamados processos de avaliação da produção acadêmica, dos quais dependem a conservação do emprego, a ascensão na carreira e a obtenção de financiamento de pesquisas, são baseados na quantidade de publicação de artigos e no comparecimento a congressos e simpósios; b) a quantidade de "pontos" obtidos por um pesquisador também depende de que consiga publicar seus artigos nos periódicos científicos definidos hierarquicamente pelo ranking; c) os grandes centros de pesquisa só conseguem financiamentos públicos e privados se continuamente "provarem" que estão alcançando novos conhecimentos, uma vez que a avaliação deixou cada vez mais de ser feita pelos pares e passou a ser determinada pelos critérios da eficácia e da competitividade (outro sinal de nossa heteronomia) (Chauí, 2003, p. 10). 
Os critérios de aferição da produção acadêmica abstraem as especificidades de cada área de conhecimento no processo de produção científica e cultural. Ademais, ocorre uma abstração das condições de produção da ciência em cada país ou região do mundo. Uma rápida observação dos maiores índices de publicações e de citações mostra que elas se concentram na América do Norte e Europa, e o pior índice h é o de países do continente africano, de onde se depreende que existe uma relação entre a chamada produtividade acadêmica e as condições econômicas de cada região (Marques, 2013, p. 39). Relacionada ao controle das publicações indiretamente, por meio do ranqueamento de veículos de divulgação, pode-se inferir que, em resposta às demandas do capital, tem havido uma redução de espaço na universidade pública para a produção de ciência e tecnologia que não vise à produção de mercadorias, mas ao desenvolvimento humano, e isso tem determinado a produção científica, cultural e tecnológica do docente. Tal constatação só reflete, na universidade em estudo, uma tendência mundial:

Essa fórmula de avaliação produtivista associada à distribuição de recursos gerou um aumento importante no número de pesquisas na Inglaterra. Entretanto, é significativa a crítica daqueles que consideram que a eficiência vem sendo construída em detrimento da autonomia profissional dos docentes e pesquisadores, havendo uma considerável perda de seu poder de decisão sobre matérias curriculares e pedagógicas e notadamente na seleção e priorização das áreas e temas de pesquisa. Em consequência do modelo avaliativo, as áreas prioritárias de pesquisa vêm frequentemente definidas pelo mercado, especialmente pela indústria, e devem responder às exigências utilitárias do curto prazo. As pesquisas nas áreas tecnológicas são valorizadas, pois a indústria tem recorrentes necessidades e urgências de seus produtos, porém ficam enfraquecidas as investigações básicas, em geral bem mais longas e de aplicação muitas vezes indefinida, e as áreas de conhecimento que têm menor apelo mercadológico, como humanidades e artes (Dias Sobrinho, 2003, p. 64).

No que tange ao cumprimento das tarefas acadêmicas, a precarização deve-se a uma política de reposição insuficiente ou deficiente de professores aposentados e demissionários, o que significa um maior número de turmas assumidas por docentes, bem como maiores responsabilidades junto da instituição. Com o desdobramento dessa nova condição, ocorre a redução do tempo dedicado à pesquisa, à extensão e às atividades como publicação, participação em congressos e orientação. A ampliação da carga horária do magistério, em detrimento da pesquisa e da extensão, tem se expandido como estratégia para a administração do problema da falta de professores, em decorrência de aposentadorias e demissões. No caso dos professores dos estágios supervisionados nas licenciaturas, a reitoria contabiliza como efetivo 
trabalho docente $10 \%$ da carga horária de estágios e $25 \%$ da carga horária de práticas de ensino, podendo chegar a contabilizar até $45 \%$ das horas de estágio dos currículos dos alunos como trabalho efetivo de magistério. A reitoria não considera como atos de trabalho remunerados a averiguação da presença dos alunos nas escolas básicas nos horários de estágio, a correção dos relatórios, o atendimento de supervisão, sob a justificativa de que estágio não constitui aula. Entretanto, os estágios são atividades didáticas, constitutivas do trabalho docente, tanto quanto as aulas, demandando preparação, dedicação e estudos sob responsabilidade dos especialistas em estágios supervisionados e práticas como componentes curriculares (UNESP, 1998).

Destacamos, enfim, o ensino à distância, que tende a aumentar o número de alunos atendidos, ampliando a tarefa do professor e rompendo o princípio da relação presencial com os alunos, que é a especificidade da relação interpessoal caracterizada no magistério. Se, por um lado, deve-se considerar que as tecnologias da informação e da comunicação podem constituir mais um recurso didático, com grandes potencialidades de uso para o professor, por outro, não se pode deixar de considerar que elas não substituem o docente pessoalmente na sala, pois é na relação dialógica e presencial do professor com cada aluno, e entre os alunos na presença do professor, que se efetiva a atividade de reelaboração do conhecimento científico, sob a mediação do docente, o qual planeja e estabelece o confronto entre o senso comum do aluno e o conhecimento científico. As tecnologias de informação e comunicação não substituem o professor numa relação de ensino, supervalorizando os recursos de aprendizagem em detrimento do professor e do aluno, protagonistas da indissociável relação ensino-aprendizagem (Barreto, 2004). O ensino à distância introduz outros conceitos, como aula, recurso didático, material didático e outros a partir do fundamento da separação entre o ensino e a aprendizagem. Nesses termos, aparecem as figuras do facilitador da aprendizagem, o gerente da classe ou o seu monitor, em substituição à figura do professor. Portanto, o ensino à distância viabiliza o trabalho em tempo parcial, a subcontratação e a terceirização - enfim, a precarização da docência.

Tal processo de precarização recai, de maneira diferenciada, sobre os docentes com uma trajetória constituída na universidade, bem como sobre os ingressantes na carreira. Os primeiros sofrem injunções com vistas à adequação aos novos parâmetros avaliativos do trabalho acadêmico, que ocasiona desgastes físicos e emocionais, podendo levar ao afastamento de intelectuais no auge da carreira, por meio da aposentadoria. E isso se intensifica devido aos ataques que a categoria tem sofrido no que tange às condições de trabalho, à restrição de direitos e às perdas salariais. Quando adquire o tempo para aposentar esse profissional deve optar, dentre as alternativas em que sempre há perdas: o professor com tempo para aposentar perde ao adiar o momento de descanso e fruição, permanecendo na universidade na condição de trabalhador na ativa ou 
aposentado em trabalho voluntário; ou quando e aposenta e reingressa por meio de novo concurso para incrementar os ganhos, uma vez que há a tendência de fim das aposentadorias integrais, devido a políticas como o São Paulo Previdência (SPPREV) (UNESP, 2006). Ademais, os planos de carreira e de avaliação de desempenho não valorizam a trajetória pregressa, pois se concentram nas atividades atuais do docente, desconsiderando as contribuições anteriores e as demandas individuais da atual fase da carreira (UNESP, 2009a). Outra expressão da precarização do trabalho docente são as constantes mudanças das leis previdenciárias, o que impede os docentes de planejarem o momento de sua aposentadoria. Na Unesp, esses profissionais foram submetidos, nas últimas duas décadas, ao regime Edunesp4, à reforma previdenciária federal de 2003, ao SPPREV (São Paulo, 2007; Brasil, 1998b, 1999 e 2003). Com tantas mudanças nos regimes previdenciários, os docentes veem-se impossibilitados de sequer prever, quanto mais planejar, o momento da aposentadoria e sua vida nessa nova fase da vida.

Os docentes em início da carreira são capturados pela lógica produtivista e pela competitividade, numa conjuntura de restrição de postos de trabalho. Por vezes, começam sua carreira na iniciativa privada, depois aceitam o trabalho nas universidades públicas, nas condições de voluntário, bolsista, conferencista, substituto ou professor bolsista pós-doutor, destituídos de direitos do trabalho. Com isso, produz-se uma hierarquização no seio da categoria docente, que é um fator de fragmentação da base sindical. Os novos requisitos para o ingresso no magistério público do ensino superior condicionam os professores a cumprir outros requisitos além da titulação e da experiência, como a internacionalização (UNESP, 2009, p. 27), os quais, por vezes, ocupam muito tempo, gerando um obstáculo à participação do docente nas entidades de classe.

No âmbito da extensão, impõe-se que os professores assumam projetos e convênios com o Ministério da Educação (MEC), de modo a oportunizar a participação em projetos do ministério, com a Secretaria de Educação do estado de São Paulo ou com a Secretaria Municipal de Educação paulistana, e parcerias público/privadas no interior da universidade, as quais lhes proporcionam ganhos extras sob a forma de bolsas. Os docentes que se dedicam a essas atividades acabam por exercer um trabalho de extensão que consiste na gestão de recursos humanos e materiais, como se fossem empreendedores, podendo levar a uma apropriação da universidade pública como um escritório de execução de políticas públicas governamentais, advindas dos diferentes entes federados. Entendemos que a apropriação da universidade como entidade executora de políticas não articuladas com a pesquisa e com o ensino pode desvirtuar sua natureza de instituição educativa, de produção de conhecimentos, de formação de massa crítica e de qualificação profissional, pois impõe uma forma de extensão submetida às necessidades imediatistas do Estado, executando políticas públicas. 


\section{Considerações finais}

No seio da categoria docente, a alienação institui-se de diversas maneiras. Destaque-se como decorrência do processo de estranhamento entre trabalhador e trabalho o fato de os docentes que ocupam os cargos administrativos planejarem e implantarem a avaliação institucional de forma reducionista. Ao realizarem tal avaliação, consideram o trabalho abstraído de suas especificidades, homogeneizado, na forma de quantidade de atividades realizadas, independentemente de sua natureza e de suas consequências para a sobrevivência da universidade pública, gratuita, laica e de qualidade social. A avaliação do trabalho do docente dá-se por meio da aferição numérica de aspectos não mensuráveis, como a qualidade das atividades. Assim, seu único meio é recorrer ao número de atividades, sem se referir a seu conteúdo, ocasionando perda na qualidade desse trabalho.

Outra manifestação da alienação está na aceitação tácita, pela comunidade acadêmica, do ensino virtual enquanto modalidade equivalente ao ensino presencial, quando, na verdade, trata-se de aprendizagem sem ensino, transmutando-se o trabalho do professor da atividade de ensino para o gerenciamento das classes. Isso caracteriza uma mudança do conteúdo do trabalho docente, independentemente da discussão sobre a sua eficácia pedagógica. Aqui a atividade laboral do docente tem sua especificidade, a qual se perde numa relação mediada não mais pelos conteúdos, mas por determinadas tecnologias da informação e da comunicação. Entretanto, informação, comunicação e conhecimento são elementos diferentes e não equivalentes. Tratá-los como equivalentes constitui fetichização (Marx, 1998). Da mesma forma, na dimensão da pesquisa - que é uma das atribuições básicas da universidade pública - o produtivismo pressupõe uma percepção individualista do trabalho, sem consciência de classe, podendo levar o docente à ilusão de que está fazendo ciência, quando, na verdade trata-se apenas de publicação per si e que não implica necessariamente a produção de conhecimento validado cientificamente, podendo ser antes glosa, reprodução ou até mesmo repetição do já dito por meio da paráfrase (Orlandi, 1987).

Entretanto, tal processo de alienação da categoria docente não se dá sem a sua resistência, que é parte de um processo de luta da classe trabalhadora em geral por sua emancipação em relação ao capital. Esse processo jamais se pode completar, pois não logra êxito em dissimular a dura realidade da exploração capitalista. Constatamos, enfim, que a precarização do trabalho dos docentes do ensino superior está intimamente articulada à avaliação institucional, que materializa na universidade os referenciais que orientaram a reforma do Estado no neoliberalismo, reconstituindo-o como Estado mínimo, fortemente avaliador e controlador e cada vez mais retraído no financiamento. Assim, as universidades públicas se convertem em quase mercados - produzindo e 
vendendo produtos e serviços ou celebrando convênios, segundo o ordenamento jurídico das parcerias público-privadas, transformando os docentes em captadores de recursos e produtores de "produtos tecnológicos, científicos e artísticos", além de convertê-las em agência de execução de políticas estatais. Assim, hoje, lutar pela causa da superação da alienação, sob a forma de precarização do trabalho docente do ensino superior público, para além de uma luta corporativa, confunde-se com a luta pela própria universidade pública, estatal, gratuita, laica e de qualidade socialmente referenciada.

Resumen Presentamos parte de la investigación sobre la precarización del trabajo docente en Brasil. Trata-se de un texto de profundización de la discusión sobre docencia en el enseño superior en el contexto actual. La hipótesis es la de que esos docentes son sometidos a la alienación y a la precarización del trabajo, por medio de políticas de reclutamiento, selección, contratación y evaluación que os destituyen del controle sobre el trabajo. Con base en el referencial del materialismo histórico y dialectico, utilizamos el análisis documental para estudiar el caso de una universidad estadual. Identificamos como indicios de la precarización del trabajo docente: las aplicaciones de evaluación institucional para gestión del personal docente; la redacción de los cuadros; la sustitución de disciplinas por prácticas profesionales en licenciaturas; el enseño a la distancia; la carencia de políticas de valorización del aposentado; y las políticas que ponen a los activos a lógica productivista.

Palabras clave enseño superior; intelectuales; universidad; trabajo docente; política educacional.

\section{Notas}

1 Universidade Estadual Paulista "Júlio de Mesquita Filho", Programa de Pós-graduação em Educação, São Paulo, Brasil.

<aurearc@rc.unesp.br>

Correspondência: Avenida 22A, 1.037, Vila Indaia, CEP 13506-705, Rio Claro, São Paulo, Brasil.

2 Todos os homens são intelectuais - possuem a faculdade do pensamento -, mas nem todos desempenham na sociedade a função de intelectuais. Quando se distingue intelectuais de não intelectuais, retoma-se a divisão primeva do trabalho em concepção e execução, e faz-se referência, na realidade, tão somente à imediata função social da categoria profissional dos intelectuais, isto é, leva-se em conta a direção sobre a qual incide o peso maior da atividade profissional específica (Gramsci, 1991). 
3 A alienação é o processo de perda do controle e do conteúdo do trabalho pelos trabalhadores no capitalismo, aprofundando-se a cada geração. Destacamos que o estranhamento entre o trabalhador e o produto de seu trabalho, a divisão social do trabalho e a naturalização de produções que são sociais leva o homem a não reconhecer naquele produto o trabalho pregresso e, até mesmo, a ser dominado pela sua produção, em vez de dominá-la, crendo que ela tem existência própria, autônoma. (ver Marx, 1984, p. 38).

4 Edunesp foi um regime criado na Unesp para reger os contratos de professores contratados em Regime de Dedicação Integral à Docência e à Pesquisa (RDIDP), entretanto, foi extinto, por que a legislação do trabalho brasileira só permite a contratação de trabalhadores no Brasil sob dois regimes: como estatutário, ou submetido à Consolidação das Leis do Trabalho.

\section{Referências}

BARRETO, Raquel G. Tecnologia e educação: trabalho e formação docente. Educação e sociedade, Campinas, v. 25, n. 89, p. 1181-1201, set./dez. 2004.

BRASIL. Plano diretor da Reforma do Estado. Brasília, 1995. Disponível em: <www.bresserpereira. org.br/documents/mare/planodiretor/plano diretor.pdf>. Acesso em: 13 nov. 2007.

BRASIL. Ministério da educação. Lei n ${ }^{\circ} 9424$ de 1996. Estabelece o Fundo de desenvolvimento e manutenção do Ensino Fundamental e valorização do magistério. Diário Oficial da União, Seção 1, 26 de dezembro de 1996, p. 28442. Disponível em: <www.planalto. gov.br>. Acesso em: 2 fev. 2010.

BRASIL. Presidência da República. Casa Civil. Subchefia para Assuntos Jurídicos. Lei $\mathrm{n}^{\circ}$ 9.608, de 18 de fevereiro de 1998a. Dispõe sobre o serviço voluntário e dá outras providências. Diário Oficial da União, 19 de fevereiro de 1998. p. 2. Disponível em: <http:// pesquisa.in.gov.br/imprensa/jsp/visualiza/ index.jsp? jornal $=1 \&$ pagina $=30 \&$ data $=19 /$ 02/1998 >. Acesso em: 3 mar. 2010.

BRASIL. Presidência da República. Casa Civil. Subchefia para Assuntos Jurídicos. Emenda Constitucional $\mathrm{n}^{\circ} 20$ de 15 de dezembro de 1998b. Modifica o sistema de previdência social, estabelece normas de transição e dá outras providências. Diário Oficial da União, 16 de dezembro de 1998 (CADERNO ELETRÔNICO). Disponível em: <http://legislacao. planalto.gov.br/legisla/legislacao.nsf/Viw_ Identificacao/emc\%2020-1998?OpenDocument>. Acesso em: 28 out. 2013.

BRASIL. Presidência da República. Casa Civil. Subchefia para Assuntos Jurídicos. Lei 9.876, de 26 de novembro de 1999. Dispõe sobre a contribuição previdenciária do contribuinte individual, o cálculo do benefício, altera os dispositivos das Leis $\mathrm{n}^{\circ} 8212$ e 8213 , ambas de 24 de julho de 1991, e dá outras providências. Diário Oficial da União, 29 de novembro de 1999, p. 1 (EDIÇÃO EXTRA) Disponível em: <http://legislacao.planalto. gov.br/legisla/legislacao.nsf/Viw_Identificacao/ lei\%209.876-1999?OpenDocument>. Acesso em: 28 out. 2013.

BRASIL. Presidência da República. Casa Civil. Subchefia para Assuntos Jurídicos. Emenda Constitucional $\mathrm{n}^{\circ} 41$ de 19 de dezembro de 2003. Modifica os arts. 37, 40, 48, 96, 149 e 201 da Constituição Federal, revoga o inciso IX do parag. 3 do ar. 142 da Constituição Federal e dispositivos da Emenda Constitucional n ${ }^{\circ} 20$ de 15 de dezembro de 1998 e dá outras providencias. Diário Oficial da União, 31 de dezembro de 2003, p. 1. Disponível em: 
<http://legislacao.planalto.gov.br/legisla/ legislacao.nsf/Viw_Identificacao/emc \% 20412003?OpenDocument>. Acesso em: 28 out. 2013.

BRASIL. Presidência da República. Casa Civil. Subchefia para Assuntos Jurídicos. Lei 11.079 de 30 de dezembro de 2004. Institui normas gerais para licitação e contratação de parceria público-privada no âmbito da administração pública. Diário Oficial da União, 31 de dezembro de 2004, p. 6 Disponível em: $<$ http://legislacao.planalto.gov.br/legisla/ legislacao.nsf/Viw_Identificacao/lei \% 20 11.079-2004? OpenDocument>. Acesso em: 28 out. 2013.

BRASIL. Presidência da República. Casa Civil. Subchefia para Assuntos Jurídicos. Lei n ${ }^{\circ} 11.494$ de 20 de junho de 2007. Regulamenta o Fundo de Manutenção e Desenvolvimento da Educação Básica e de Valorização dos Profissionais da Educação - FUNDEB, de que trata o art. 60 do Ato das Disposições Constitucionais Transitórias; altera a Lei no 10.195, de 14 de fevereiro de 2001; revoga dispositivos das Leis nos 9.424, de 24 de dezembro de 1996, 10.880, de 9 de junho de 2004, e 10.845, de 5 de março de 2004; e dá outras providências. Diário Oficial da União, 21 de junho de 2007, p. 7 Disponivel em: <http://legislacao. planalto.gov.br/legisla/legislacao.nsf/Viw_ Identificacao/lei\%2011.494-2007?Open Document> Acesso em: 21/7/2016.

COELHO, Ildeu M. Educação superior: por uma outra avaliação. In: DOURADO, Luiz F.; CATANI, Afrânio M.; OLIVEIRA, João F. de (orgs.) Políticas e gestão da educação superior: transformações recentes e debates atuais. São Paulo: Xamã; Goiânia: Alternativa, 2003.

CHAUÍ, Marilena. A universidade pública sob nova perspectiva. Revista Brasileira de Educação, Rio de Janeiro, n. 24, p. 5-15, set./nov. 2003.

DIAS SOBRINHO, José. Avaliação: políticas educacionais e reformas da educação superior. São Paulo: Cortez, 2003.

FREITAS, Helena C. L. A reforma do Ensino superior no campo da formação dos profissionais da educação básica: as políticas educacionais e o movimento dos educadores. Educação e Sociedade, São Paulo, n. 68, dez., p. 18-42, 1999.

FREITAS, Helena C. L. A (nova) política de formação de professores: a prioridade postergada. Educação e sociedade, São Paulo, n. 100, v. 28, número especial, p. 1203-1230, 2007.

GILSON, Etienne. A filosofia na idade média. São Paulo: Martins Fontes, 2001. (Paidéia).

GRADELLA JÚNIOR. Osvaldo. Sofrimento psíquico e trabalho intelectual. Cadernos de Psicologia Social do Trabalho, São Paulo, v. 13, n. 1, p. 1333-148, 2010.

GRAMSCI, Antonio. Os intelectuais e a organização da cultura. Rio de Janeiro: Civilização Brasileira, 1980.

MARQUES, Fabrício. Os limites do índice-h. Pesquisa Fapesp, São Paulo, v. 207, p. 35-39, maio de 2013.

MARX, Karl. A ideologia alemã (primeira parte). Teses de Feuerbach. São Paulo: Moraes, 1984.

MARX, Karl. O capital. Rio de Janeiro: Civilização Brasileira, 1998. (Livro I; v. 1).

Instituto Nacional de Estudos e Pesquisas Educacionais Anísio Teixeira (INEP). Resumo técnico do censo da educação superior de 2009. Disponível em: <www.inep.gov.br/superior/ censosuperior/relatorio_tecnico.htm $>$. Acesso em: 9 fev. 2011.

SCHWARZT, Ives. Trabalho e uso de si. Pro-Posições, Campinas, vol. 11, n. 2, n. 32, p. 34-50, jul.2000.

ORLANDI, Eni L. P. A linguagem e seu funcionamento. 2. ed. Campinas: Pontes, 1987.

SANTOS, Lucíola L. C. P. Formação de professores na cultura do desempenho. Educação e Sociedade, São Paulo, v. 25, n. 89, p. $1097-$ -1100 , set./dez. 2004.

SÃO PAULO. Lei $n^{\circ} 12.677$ de 16 de julho de 2007. Dispõe sobre as diretrizes orçamen- 
tárias para o exercício de 2008. Publicada na Assessoria Técnico-Legislativa, 16 de julho de 2007. Disponível em: <www.planejamento. sp.gov.br/noti_anexo/files/planejamento_ orcamento/ldo/LDO_2008.pdf>. Acesso em: 24 jul. 2016.

SILVA Jr., João R.; SGUISSARDI, Valdemar. Novas faces da educação superior no Brasil: reforma do Estado e mudanças na produção. 2. ed. rev. São Paulo: Cortez/CDAPH-IFAN/ USF, 2001.

SOUZA, José G. A dimensão social e política do conhecimento (ciência ou consciência?). Revista Formação, São Paulo, v. 1, n. 15, p. 167-172, 2008.

UNESP. Resolução n ${ }^{\circ} 84$ de 4/11/1999a. Estabelece as diretrizes para a atuação da Comissão Permanente de Ensino (CPA). Disponível em: <www.unesp.br/cpa/mostra_arq_multi. php?arquivo $=4790>$ Acesso em: 19 jul. 2016.

UNESP. Resolução 85 de 4 de novembro de 1999b. Dispõe sobre os regimes de trabalho de docente da UNESP. Disponível em: <www. ibilce.unesp.br/Home/.../res_regimerabalho docente_rdidp_rtc_rtp > Acesso em: 19 jul. 2016.

UNESP. Portaria 6 de 7 de janeiro de 2000, que regulamenta a resolução 85 de 1999. Disponível em: <www.ibilce.unesp.br/Home/ Administracao456/.../portariaunesp06_2000. doc >. Acesso em: 19 jul. 2016.
UNESP. CEPE Conselho de Ensino, Pesquisa e Extensão/Pro-Reitoria de Graduação: Regulamentação do artigo 57 da LDB: relatório final de comissão constituída em sessão de 10/02/1998. 13p. Mimeografado. Disponível em: <www2.fcfar.unesp.br/Home/Graduacao/ regulamentacao-art-57-ldb.doc $>$. Acesso em: 19 jul. 2016.

UNESP. Resolução Unesp n ${ }^{\circ} 62$, de 31 de outubro de 2006. Dispõe sobre a prestação de serviço voluntário no âmbito da UNESP e dá outras providências. Disponível em: <www. feb.unesp.br/Home/Administracaol10/DTA/ SecaoTec.Academica/RESOLUCAO_UNESP_ N_62-2006-Dispoe_sobre_servico_voluntario. pdf>. Acesso em: 2 out. 2013.

UNESP. Plano de desenvolvimento institucional. São Paulo: UNESP, 2009. mimeografado. Disponível em: <http://unesp.br/ape/ pdi/execucao/index.php $>$. Acesso em: 10 fev. 2011.

UNESP. Cadernos do 1 Fórum das Grandes Áreas do Conhecimento: avaliação do trabalho docente na UNESP. Aguas de Lindóia 30/5 a 1/6 de 2011. Disponível em: <www. unesp.br/forum-grandes-areas/I/paginas/ pdf/material/caderno.pdf $>$. Acesso em: 3 abr. 2015.

VERGER, Jaques. As universidades na idade média. São Paulo: Unesp, 1990.

Recebido em 17/01/2015

Aprovado em 08/12/2015 